\title{
Patient Satisfaction and Associated Factors During COVID-19 Pandemic in North Shoa Health Care Facilities
}

This article was published in the following Dove Press journal: Patient Preference and Adherence

\author{
Berhanu Senbeta Deriba (iD) \\ Tinsae Abeya Geleta' \\ Rebik Shukure Beyane (D) \\ Ahmed Mohammed' \\ Mengistu Tesema' \\ Kemal Jemal (iD ${ }^{2}$ \\ 'Salale University, College of Health \\ Sciences, Department of Public Health, \\ Fitche, Ethiopia; ${ }^{2}$ Salale University, \\ College of Health Sciences, Department \\ of Nursing, Fitche, Ethiopia
}

Correspondence: Kemal Jemal Email olifanjemal@gmail.com
Background: Patient satisfaction is an indicator of healthcare quality service and involved as an outcome measure. Quality of healthcare service and patient satisfaction has been affected by the current coronavirus disease 2019 (COVID-19) pandemic. It induced uncertainness and shortage of medical supplies due to a limited global movement. Therefore, this study aimed to assess patient satisfaction and associated factors among chronic patients who had a follow-up in North Shoa healthcare facilities.

Methods: An institutional-based cross-sectional study was used to select 410 study participants through a systematic random sampling technique. Data were collected by a structured interviewer-administered questionnaire, entered into Epi Info version 7, and transported to SPSS version 23 for analysis. Bivariable and multivariable logistic regressions were used to identify the factors associated with satisfaction. The odds ratio with a $95 \%$ confidence interval was computed, and p-value $<0.05$ was considered statistical significance in the multivariable model.

Results: The overall level of patient satisfaction was $44.6 \%$. The presence of sign and direction indicators $(\mathrm{AOR}=3.26,95 \% \mathrm{CI}=1.1,9.92)$, obtaining some ordered drugs $(\mathrm{AOR}=3.7$, 95\% $\mathrm{CI}=1.1$, 12.54), getting alcohol for hand cleaning $(\mathrm{AOR}=2.66,95 \%$ $\mathrm{CI}=1.1,6.65)$, obtaining sanitizer for hand cleaning ( $\mathrm{AOR}=4.45,95 \% \mathrm{CI}=1.72,11.52)$, and maintaining social distancing $(\mathrm{AOR}=2.63,95 \% \mathrm{CI}=1.21,5.70)$ were factors associated with patient's satisfaction.

Conclusion: The level of patient satisfaction was very low during a COVID-19 pandemic. The presence of sign and direction indicators, availability of drugs, social distancing, availability of alcohol, and sanitizer were factors associated with patient satisfaction. The intervention targeted at increasing patient satisfaction and improving the quality of service during COVID-19 through maintaining social distancing and availing alcohol or sanitizers is necessary.

Keywords: patient satisfaction, COVID-19, associated factors, Ethiopia

\section{Background}

Satisfaction is a unit of similarity between patient beliefs of ideal care and their observations of real care received. ${ }^{1}$ Patient satisfaction is the degree to which patients are pleased with their healthcare, both inside and outside healthcare facilities. ${ }^{2}$ It gives providers insights into various healthcare features, including the effectiveness of their care and their level of understanding. ${ }^{3}$ Understanding the patients, caregivers, and families from their perspective is an opportunity to reflect provider behavior (politeness and respect), improvement of healthcare services, and patient outcomes. $^{4,5}$ 
In most low-resourced countries, healthcare systems suffer from severe shortages of financing, low equity and quality, and poorly prepared to meet the challenges of the current COVID-19 pandemic. $^{6}$ The COVID-19 is an acute respiratory tract infection that emerged in late $2019 .^{7}$ It has flu-like symptoms, such as fever, cough, the difficulty of breathing, fatigue, and muscle pain. ${ }^{8}$

The global health coverage faced critical challenges with increased non-communicable diseases adding to the global burden of diseases and may not successful care performance noticed as an ambitious plan. ${ }^{9-11}$ Additionally, the COVID-19 disease is one of the global burdens affecting $99 \%$ of chronic disease patients, which have a preexisting condition (heart disease, high blood pressure, diabetes, advanced age, and kidney disease) have been dying due to the current pandemic. ${ }^{12}$

World Health Organization (WHO) announced in March 2020 to minimize community transmission of COVID-19 through practicing social distance, frequent hand washing, and reduce population density in a healthcare setting as a means of COVID-19 prevention. ${ }^{13}$ Ethiopia is at high risk of transmitting the pandemic; our communities are densely populated with informal dwellings, lack of access to clean water, shared sanitation facilities, high social mixing levels, and transient residents. ${ }^{14}$ The poor healthcare systems may aggravate the outbreak's impact and limit the capacity to conduct adequate surveillance and control. ${ }^{15}$

Evaluating the extent to which patients are satisfied with healthcare services is clinically significant, as satisfied patients are more likely to comply with treatment. ${ }^{16}$ In contrast, the effect of COVID-19 has been reducing procedure and treatment adherence, increase treatment dissatisfaction, and discontinue their treatment follow-up. ${ }^{17,18}$ The outcome of unmet client needs can be problematic since it causes a lack of confidence in the healthcare system and healthcare providers. ${ }^{19,20}$

In resourced countries, patient needs during COVID-19 can be managed by telemedicine, which is vital to deliver methods of infection control and compliance to social distancing, appropriate use of mask and hand hygiene, or sanitizer. ${ }^{21,22}$ Telemedicine also increases healthcare coverage through emails, telephone, and video calls to minimize patient travel to healthcare facilities, time-saving, and cost-effective with increased patient satisfaction. ${ }^{23-25}$

The Ethiopian Federal Ministry of Health implemented Compassionate Respectful Care (CRC) as one of the healthcare sector transformation plan to increase client satisfaction and health service quality. ${ }^{26}$ However, the satisfaction of chronic patients and quality of service is currently affected by the COVID-19 pandemic, imposing a shortage of medical supplies and uncertainness of being infected due to limited global movement from one country to another.

As COVID-19 continues to spread, health professionals and the COVID-19 Prevention and Control Committee may become busy and regular service can be forgotten. These circumstances can extremely affect the quality of health service and client satisfaction exceptionally from the previous one. Patient satisfaction is considered one of the anticipated outcomes of healthcare, and it is directly related to the utilization of health services. Nevertheless, there is no adequate information on users' perception of the healthcare facilities' services after the emergence of COVID-19, especially in Ethiopia. Therefore, this study aimed to assess patient satisfaction and associated factors during the COVID-19 pandemic among chronic patients who had follow-up at public health facilities in the North Shoa Zone, Oromia region, Ethiopia.

\section{Methods}

\section{Study Design, Period and Area}

An institutional-based cross-sectional study was conducted from May 1 to June 30, 2020, in North Shoa public health facilities. The North Shoa zone is one of 20 zones found in the Oromia regional state. It has 13 woredas and two towns' administration, with a total of 1.6 million populations. The zone has five public hospitals and 57 health centers that give services for the catchment area population.

\section{Source and Study Population}

All patients with chronic disease who had follow-up at North Shoa public health facilities in the North Shoa Zone were the source population. All randomly selected patients with chronic disease who had follow-up at North Shoa public health facilities in the North Shoa Zone were the study population.

\section{Inclusion and Exclusion Criteria}

All patients whose ages greater than 15 years and who have a chronic disease (HIV/AIDS, tuberculosis, cardiovascular disease, cancer, diabetes mellitus, chronic respiratory disease, and chronic musculoskeletal diseases) follow-up for more than six months at North Shoa public 
health facilities were included in the study. Those patients with chronic diseases who were seriously sick (unable to speak) and suspected COVID-19 (who had come for chronic disease follow-up and have signs and symptoms' of COVID-19 during the screening) were excluded from the study.

\section{Sample Size Determination and Sampling Procedure}

The sample size was calculated using a single population proportion formula, taking a proportion of $58.3 \%$ of the study conducted in Bahirdar city. ${ }^{27}$ Considering a $95 \%$ confidence interval and a 5\% marginal error with a $10 \%$ non-response rate, the final sample size was 412 . The study was conducted in three hospitals and four health centers selected purposely because they have a high number of patients with chronic diseases in the North Shoa zone. The total estimated number of patients for one month obtained from chronic disease patients' department registration books was 10,800 (2500 from Fitche General Hospital, 2000 from Kuyu General Hospital, 2100 from Chancho Primary Hospital, 1000 from Debire Tsige Health Center, 1200 from Muke Turi Health Center, 1200 from Wara Jarso Health Center and 800 Hambiso Health Center). The proportional allocation was done by multiplying the number of chronic disease patients from all hospitals and health centers $(10,800)$ with a total sample size $(n=412)$, divided by the total number of chronic patients attending each health facility. The study participants were selected at each public health facility using a systematic random sampling technique every obtained interval for each health facility using patient registration as a sampling frame. The first participant was selected by the lottery method, depending on the obtained interval.

\section{Data Collection Tools and Procedure}

Data was collected through direct face to face interviews by semi-structured questionnaires, which were developed from earlier similar articles. ${ }^{27-29}$ The questionnaire was prepared in English and translated to Afan Oromo and Amharic language for better understanding for both data collectors and respondents, and translated back to the English version to check the consistency. The questionnaire has socio-demographic characteristics, servicerelated inquiries, the relationship between the service providers and patients, the physical environment, COVID-19 prevention, and control related variables questions. Seven
BSC nurses and four public heaths were recruited for data collection and supervision, respectively. Four days of training were given to data collectors and supervisors on the study's objective, the questionnaire's contents, confidentiality, respondents' right, and how to collect data. The pretest was done among $21(5 \%)$ of the sample at Kuyu Health Center. Data collectors and supervisors were discussed with principle investigators on the questionnaire and modified for any inconsistencies and ambiguity before actual data collection.

We collected data from non-communicable and communicable chronic diseases, including HIV/AIDS, tuberculosis, cardiovascular disease, cancer, diabetes mellitus, chronic respiratory disease, and chronic musculoskeletal diseases.

The outcome of patient satisfaction was measured using satisfaction measurement tools. It contains 34 items on a five-point Likert scale scored from 1 to $5(1=$ strongly disagree, $2=$ disagree, $3=$ neutral, $4=$ agree, and $5=$ strongly agree), which together yield a minimum of 34 and a maximum of 170. A response to 34 measuring items was added and converted to give an individual level of satisfaction score from $1 \%$ to $100 \%$ for each item. Patients who scored $75 \%$ and above on 34 satisfaction measuring items were satisfied, and those who scored less than $75 \%$ were unsatisfied. $^{28,29}$

\section{Data Processing and Analysis}

After data collection, data were checked for completeness and coded, cleaned, and entered into Epi Info version-7 and transported to SPSS version 23 for data cleaning and analysis. Descriptive statistics such as tables, graphs, pie charts, and proportions were used to present the data. Patients who have satisfied were scored as "1" whiles those who have dissatisfied were scored as " 0 ". Bivariable and multivariable in binary logistic regression analyses were done to see the association between dependent and independent variables. The test's model goodness was checked by Hosmer-Lemeshow goodness fit, and the p-value for the model fitness test was 0.850 .

\section{Ethical Consideration}

This study was conducted in accordance with the Declaration of Helsinki. Salale University approved the ethical clearance of verbal informed consent and assent. A support letter was granted from the North Shoa zone health office, and oral informed consent was obtained from the study participants whose age $\geq 18$ years. The assent was obtained from parents/guardians for 15 to 18 years old 
after clearing-up about the study's objective and purpose for each study participant. The privacy and confidentiality of study participants were also be maintained strictly. Data collectors were informed about coding the questionnaire and not writing the study participants' names.

\section{Results}

\section{Socio-Demographic and Economic} Characteristics of Respondents

A total of 410 chronic disease patients participated in a response rate of $99.5 \%$. Out of total study participants, $215(52.4 \%)$ were male, and $175(42.8 \%)$ of the respondents were aged more than 45 years old. More than half of the study respondents were not attended formal education, and $349(85.1 \%)$ of study participants were orthodox by religion. Oromo ethnic groups were the majority (87.1\%). Nearly two-thirds of the respondents earned $\leq 2000$ Ethiopian Birr monthly [Table 1].

Of the total study participants, one-third of the participants 139 (33.9\%) have a follow-up of HIV/AIDS cases, followed by hypertension 76 (18.5\%), tuberculosis 72 (17.6\%), and diabetes mellitus 60 (14.6\%) [Figure 1].

\section{HealthCare Services Related}

\section{Characteristics of the Study Participants}

More than two-thirds of study participants were ordered for laboratory tests, and $43.8 \%$ of study participants wait for an average of 15 to 29 minutes to get the laboratory results [Figure 2].

Nearly half 190 (46.3\%) of the respondents have free healthcare access covered by their woreda. More than twothirds of the study participants had educated to maintain their healthy life modification. More than half of the study participants 154 (53.1\%) had purchased drugs/supplies from the health facilities. X-rays or ultra-sounds were ordered for 161 (39.3\%) participants, but only 65 (40.4\%) of the study participants had obtained the ordered $\mathrm{x}$-rays or ultrasounds at public health facilities. Threefourth of clients reported as the health facilities they are attending had no sign and direction indicators [Table 2].

\section{COVID-19 Prevention and}

\section{Control-Related Characteristics of the}

\section{Study Participants}

Of the total respondents, $365(89 \%)$ of study participants have noticed the availability of water at the health facility
Table I Socio-Demographic Characteristics of Chronic Diseases Patients Who Had a Follow-Up Visit at Health Facilities in North Shoa Zone, Oromia Region, from May I to June 30, 2020

\begin{tabular}{|c|c|c|}
\hline Variables & $\begin{array}{l}\text { Number of } \\
\text { Participants }\end{array}$ & $\begin{array}{l}\text { Percent } \\
\text { (\%) }\end{array}$ \\
\hline \multicolumn{3}{|l|}{ Sex } \\
\hline Male & 215 & $52.4 \%$ \\
\hline Female & 195 & $47.6 \%$ \\
\hline \multicolumn{3}{|l|}{ Age } \\
\hline $15-24$ & 36 & $8.8 \%$ \\
\hline $25-34$ & 97 & $23.7 \%$ \\
\hline $35-44$ & 102 & $24.8 \%$ \\
\hline$>45$ & 175 & $42.7 \%$ \\
\hline \multicolumn{3}{|l|}{ Residence } \\
\hline Urban & 202 & $49.3 \%$ \\
\hline Rural & 208 & $50.7 \%$ \\
\hline \multicolumn{3}{|l|}{ Level of education } \\
\hline $\begin{array}{l}\text { Has no formal } \\
\text { education }\end{array}$ & 212 & $51.7 \%$ \\
\hline $\begin{array}{l}\text { Primary school } \\
\text { completed }\end{array}$ & 91 & $22.2 \%$ \\
\hline Grade 9-12 completed & 46 & $11.2 \%$ \\
\hline Diploma and above & 61 & $14.9 \%$ \\
\hline \multicolumn{3}{|l|}{ Marital Status } \\
\hline Married & 295 & $72 \%$ \\
\hline Widowed & 30 & $7.3 \%$ \\
\hline Single & 62 & $15.1 \%$ \\
\hline Divorced & 23 & $5.6 \%$ \\
\hline \multicolumn{3}{|l|}{ Family size } \\
\hline$\leq 5$ & 323 & $78.8 \%$ \\
\hline$>5$ & 87 & $21.2 \%$ \\
\hline \multicolumn{3}{|l|}{ Religion } \\
\hline Orthodox & 349 & $85.1 \%$ \\
\hline Protestant & 42 & $10.3 \%$ \\
\hline Wakefata & 3 & $0.7 \%$ \\
\hline Muslim & 15 & $3.7 \%$ \\
\hline Other & 1 & $0.2 \%$ \\
\hline \multicolumn{3}{|l|}{ Occupational status } \\
\hline Farmer & 166 & $40.5 \%$ \\
\hline Government employee & 71 & $17.3 \%$ \\
\hline Private employee & 39 & $9.5 \%$ \\
\hline Merchant & 30 & $7.3 \%$ \\
\hline Housewife & 67 & $16.4 \%$ \\
\hline Student & 20 & $4.9 \%$ \\
\hline Other & 17 & $4.1 \%$ \\
\hline \multicolumn{3}{|l|}{ Family monthly income } \\
\hline$\leq 2000$ & 268 & 65.4 \\
\hline $200 \mathrm{I}-5000$ & 104 & 25.4 \\
\hline $500 \mathrm{I}-8000$ & 29 & 7.0 \\
\hline$\geq 800 \mathrm{I}$ & 9 & 2.2 \\
\hline
\end{tabular}




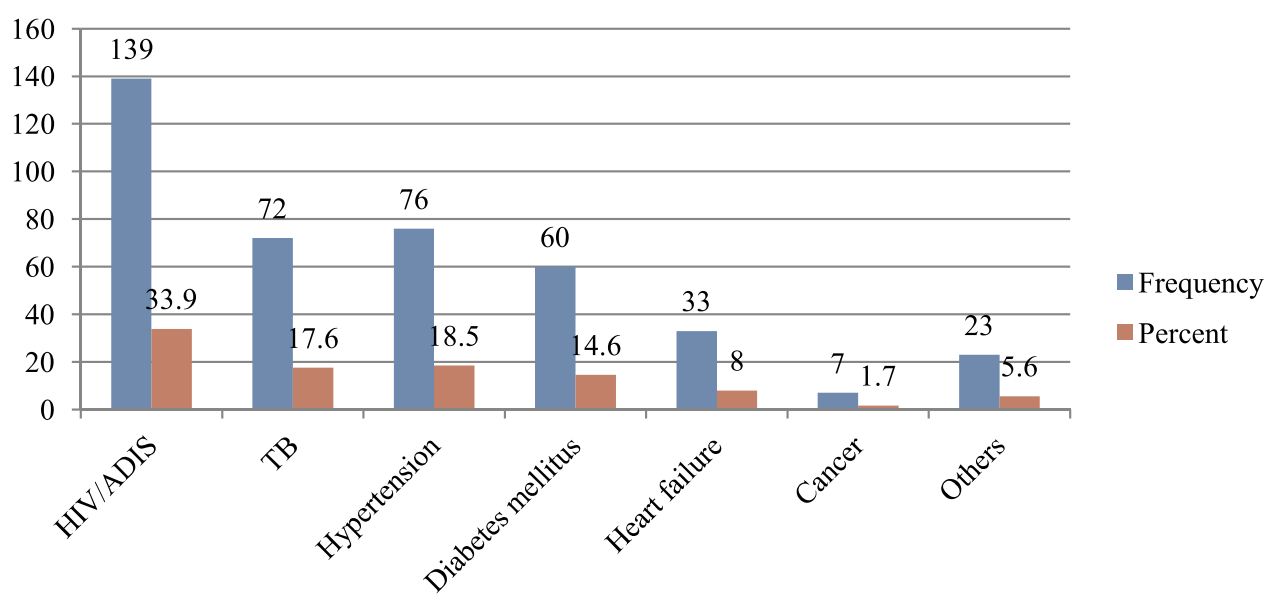

Figure I Types of chronic diseases patients who had follow-up visit at health facilities in North Shoa zone, Oromia region, from May I to June 30, 2020.

\section{Waiting time}

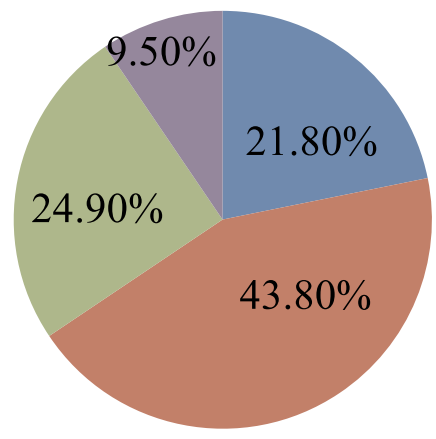

\section{1-14 minutes}

15-29 minutes

30-44 minutes

$>=45$ minutes

Figure 2 Waiting time to get laboratory services and results for chronic diseases patients who had follow-up visit at health facilities in North Shoa zone, Oromia region, from May I to June 30, $2020(n=4 \mid 0)$.

entrance and washed their hands before entry to a health facility. Nearly two-thirds of participants have observed and maintained physical distance at registration, waiting area, laboratory, and pharmacy areas. Regarding clinicians wearing gloves and masks, participants have mentioned $80.5 \%$ and $89.5 \%$ of clinicians wearing gloves and masks, respectively, while providing healthcare services. More than twothirds of healthcare facilities had no hand cleaning alcohol at the entrance of their compounds. Only $56(14.4 \%)$ of the study participants were reported the availability of COVID19 screening services at healthcare facilities [Table 3].

\section{Patient Satisfaction}

The overall patient with chronic illness satisfaction was $44.6 \%$ with a confidence interval (95\% CI: $1.40-1.49)$. On the other hand, $55.4 \%$ of study participants had dissatisfaction [Figure 3]. Regarding patient satisfaction by chronic disease category, 74 (40.4) of HIV/AIDS patients who had follow-up visits were satisfied with healthcare services. More than half of patients 98 (53.5) who had no formal education were satisfied with healthcare services. More than two-fifth of the study participants (44.8\%) who came from urban were satisfied [Table 4].

\section{Factors Associated with Patient Satisfaction}

Bivariable logistic regression was done for each independent variable, and the variables that had a statistically significant association with patient satisfaction at p-value $<0.20$ were entered into multiple logistic regressions. The presence of sign and direction indicators, obtaining some ordered drugs, getting alcohol for hand cleaning, obtaining 
Table 2 Healthcare Service-Related Characteristics of Chronic Diseases Patients Who Had a Follow-Up Visit at Health Facilities in North Shoa Zone, Oromia Region, from May I to June 30, 2020 $(n=410)$

\begin{tabular}{|c|c|c|}
\hline Variables & $\mathbf{n}$ & $\%$ \\
\hline \multicolumn{3}{|c|}{ Waiting time from registration to end of services in minutes } \\
\hline Less 30 & 242 & $59 \%$ \\
\hline $30-60$ & 113 & $27.6 \%$ \\
\hline $6 I-90$ & 40 & $9.8 \%$ \\
\hline$\geq 91$ & 15 & $3.6 \%$ \\
\hline \multicolumn{3}{|c|}{ The distance of patient home from a health facility in kilometers } \\
\hline$\leq 10$ & 222 & $54.1 \%$ \\
\hline$>10$ & 188 & $45.9 \%$ \\
\hline \multicolumn{3}{|c|}{ Was the laboratory test ordered for you? } \\
\hline Yes & 285 & $69.5 \%$ \\
\hline No & 125 & $30.5 \%$ \\
\hline \multicolumn{3}{|c|}{ Availability of ordered laboratories $(n=285)$} \\
\hline All in all & 156 & $54.7 \%$ \\
\hline Some & 108 & $37.9 \%$ \\
\hline Not at all & 21 & $7.4 \%$ \\
\hline \multicolumn{3}{|c|}{ Was the X-ray/ultrasound procedure ordered for you? } \\
\hline Yes & 161 & $39.3 \%$ \\
\hline No & 249 & $60.7 \%$ \\
\hline \multicolumn{3}{|c|}{ Availability of ordered X-ray/ultrasound procedure in hospital $(n=|6|)$} \\
\hline All in all & 65 & $40.4 \%$ \\
\hline Some & 86 & $53.4 \%$ \\
\hline Not at all & 10 & $6.2 \%$ \\
\hline \multicolumn{3}{|l|}{ Payment status } \\
\hline Free & 190 & $46.4 \%$ \\
\hline Paid & 126 & $30.7 \%$ \\
\hline Health insurance & 94 & $22.9 \%$ \\
\hline \multicolumn{3}{|c|}{ Availability of sign and direction indicator in the health facility } \\
\hline Yes & 101 & $24.6 \%$ \\
\hline No & 309 & $75.4 \%$ \\
\hline \multicolumn{3}{|c|}{ Searched water for drinking in the health facility } \\
\hline Yes & 261 & $63.7 \%$ \\
\hline No & 149 & $36.3 \%$ \\
\hline \multicolumn{3}{|c|}{ Availability of drinking water in the hospital $(n=261)$} \\
\hline Yes & 211 & $80.8 \%$ \\
\hline No & 50 & $19.2 \%$ \\
\hline \multicolumn{3}{|c|}{ Provider tell you how to maintain your health life } \\
\hline Yes & 289 & $70.5 \%$ \\
\hline No & 121 & $29.5 \%$ \\
\hline
\end{tabular}

(Continued)
Table 2 (Continued).

\begin{tabular}{|l|l|l|}
\hline Variables & $n$ & $\%$ \\
\hline \multicolumn{2}{|l|}{ Provider interview by the language you can understand } \\
\hline Yes & 347 & $84.6 \%$ \\
No & 63 & $15.4 \%$ \\
\hline Did you recommend this health facility to others? \\
\hline Yes & 302 & $73.7 \%$ \\
No & 108 & $26.3 \%$ \\
\hline Whether or not drugs/supplies are ordered for you \\
\hline Yes & 290 & $70.7 \%$ \\
No & 120 & $29.3 \%$ \\
\hline Availability of ordered drugs/supplies in hospital (n=290) \\
\hline Yes & 154 & $53.1 \%$ \\
Some & 94 & $32.4 \%$ \\
Not at all & 42 & $14.5 \%$ \\
\hline Did you go to the toilet to use the latrine? & 344 \\
\hline Yes & 66 & $16.1 \%$ \\
\hline No & $34.9 \%$ \\
\hline
\end{tabular}

sanitizer for hand cleaning, and maintaining social distancing were variables significantly associated with patient satisfaction in multivariable logistic regressions at $p$-value $<0.05$ [Table 5].

The result from multiple logistic regression analyses showed that patients who obtained the sign and direction indicators in the health facility were 3.26 times more likely to be satisfied than their counterparts ( $\mathrm{AOR}=3.26,95 \%$ $\mathrm{CI}=1.1,9.92$ ). Patients who got some parts of ordered drugs from the health facility were 3.7 times more likely satisfied than those who did not get all ordered drugs (AOR=3.7, 95\% CI=1.1, 12.54). Patients who got alcohol for hand cleaning at the health facilities entrance were 2.66 times more likely satisfied than those who did not get it (AOR=2.66, 95\% CI=1.1,6.65). Patients who obtained sanitizer for hand cleaning at the health facilities entrance were 4.45 times more likely satisfied than their counterparts $(\mathrm{AOR}=4.45,95 \% \mathrm{CI}=1.72,11.52)$. Those patients who maintain social distancing in the health facility were 2.63 times more likely satisfied than their counterparts $(\mathrm{AOR}=2.63,95 \% \mathrm{CI}=1.21,5.70)$ [Table 5].

\section{Discussion}

Overall, $44.6 \%$ of patients with chronic disease were satisfied with the service they received from health 
Table 3 COVID-19 Prevention and Control-Related Characteristics of Chronic Diseases Patients Who Had a FollowUp Visit at Health Facilities in North Shoa Zone, Oromia Region, from May I to June 30, $2020(n=410)$

\begin{tabular}{|c|c|c|}
\hline Variables & $\mathbf{n}$ & $\%$ \\
\hline \multicolumn{3}{|c|}{ Water available at the entrance of the hospital for hand washing } \\
\hline Yes & 365 & $89 \%$ \\
\hline No & 45 & $11 \%$ \\
\hline \multicolumn{3}{|c|}{ Soap available at the entrance of the hospital for hand washing } \\
\hline Yes & 331 & $80.7 \%$ \\
\hline No & 79 & $19.3 \%$ \\
\hline \multicolumn{3}{|c|}{ Alcohol available at the entrance of the hospital for cleaning of hand } \\
\hline Yes & 124 & $30.2 \%$ \\
\hline No & 286 & $69.8 \%$ \\
\hline \multicolumn{3}{|c|}{ Sanitizer available at the entrance of the hospital for cleaning of hand } \\
\hline Yes & 308 & $75.1 \%$ \\
\hline No & 102 & $24.9 \%$ \\
\hline \multicolumn{3}{|c|}{ Keeping physical distance practice in health facility's } \\
\hline Yes & 270 & $65.9 \%$ \\
\hline No & 140 & $34.1 \%$ \\
\hline \multicolumn{3}{|c|}{ Clinician wear the gloves during health caregiving } \\
\hline Yes & 330 & $80.5 \%$ \\
\hline No & 80 & $19.5 \%$ \\
\hline \multicolumn{3}{|c|}{ Clinician wear the mask during health caregiving } \\
\hline Yes & 367 & $89.5 \%$ \\
\hline No & 43 & $10.5 \%$ \\
\hline \multicolumn{3}{|c|}{ Clinician rub their hands before or after health caregiving } \\
\hline Yes & 349 & $85.1 \%$ \\
\hline No & 61 & $14.9 \%$ \\
\hline \multicolumn{3}{|c|}{ Health professionals provide health education on COVID-19 } \\
\hline Yes & 295 & $72 \%$ \\
\hline No & 115 & $28 \%$ \\
\hline \multicolumn{3}{|c|}{ Health facility provide screening service for COVID-19 } \\
\hline Yes & 351 & $85.6 \%$ \\
\hline No & 59 & $14.4 \%$ \\
\hline
\end{tabular}

facilities. This finding is similar to the study done in the Tigray region, Ethiopia $(43.6 \%){ }^{30}$ It is lower than the studies conducted at Jima university specialized hospital $(77 \%),{ }^{31}$ Ilu Ababor primary health facilities (57.9\%), ${ }^{32}$ Nekemte referral hospital (58.16\%), ${ }^{33}$ Hawassa University teaching hospital (80.1\%), ${ }^{34}$ Bahirdar Felege Hiwot referral hospital $(58.3 \%),{ }^{27}$ Debraberhan referral hospital $(57.7 \%),{ }^{35}$ Wolayita Sodo teaching hospital $(54.2 \%),{ }^{36}$ Nigeria University Calabar teaching hospital $(59.3 \%),{ }^{37}$ Nepal Chitwan medical teaching college $(75.9 \%) .{ }^{38}$ It is higher than the study conducted at Kilimanjaro hospital, Tanzania $(20 \%){ }^{39}$

This is because the health system in developing countries like Ethiopia is not ready to deliver care to chronic illness patients such as hypertension, diabetes, and other chronic diseases. It is prepared to provide better care to acute infectious and parasitic diseases. ${ }^{27}$ Moreover, this variation might be due to the study setting and time difference, ${ }^{40}$ differences in socioeconomic status, the difference in patient management strategy across the health facilities, and the use of different cutoff points to determine patient satisfaction might be other reasons of satisfaction disagreement. ${ }^{41}$

Patients who got some ordered drugs from the health facility were 3.7 times more likely satisfied than those who did not get any ordered drugs from the health facilities. It is in agreement with the studies done in Addis Abeba public hospitals, ${ }^{41}$ Yekatit 12 medical college, ${ }^{42}$ Jimma University specialized hospital, ${ }^{31}$ Iluababor zone, ${ }^{32}$ Wolayita-Sodo, ${ }^{36}$ Dabraberhan, ${ }^{35}$ and Bahardir, Ethiopia $^{43}$ where patients who did not get drugs were less satisfied than those who had ordered drugs.

The study found that unable to get ordered drugs is the main cause of patient dissatisfaction, making the poor people bypass the closest public health facilities to go to more costly private facilities or choose better quality public health facilities present at more distances. ${ }^{32}$ Traveling the long distances to get quality healthcare to the far health facilities may expose the patient to COVID-19 due to contact with many people on-road or public transportation. This may be solved by applying telemedicine in low-and middle-income countries to save time and resources, and control and prevent COVID-19 pandemic. ${ }^{21,22}$

In this study, the presence or absence of a sign and direction indicators were significantly associated with patient satisfaction. It is consistent with the studies conducted in Addis Abeba, Yekatit 12 hospital, ${ }^{42}$ where the availability of sign and diction indicator increases patient satisfaction by $98 \%$ and in Bahirdar, Ethiopia, ${ }^{43}$ in which $74 \%$ of patients dissatisfied due to the absence of sign and direction indicators. The provision of sign and direction indicators in the healthcare facilities may provide a good image for customers to access easily the room they need for healthcare services. ${ }^{44}$ 


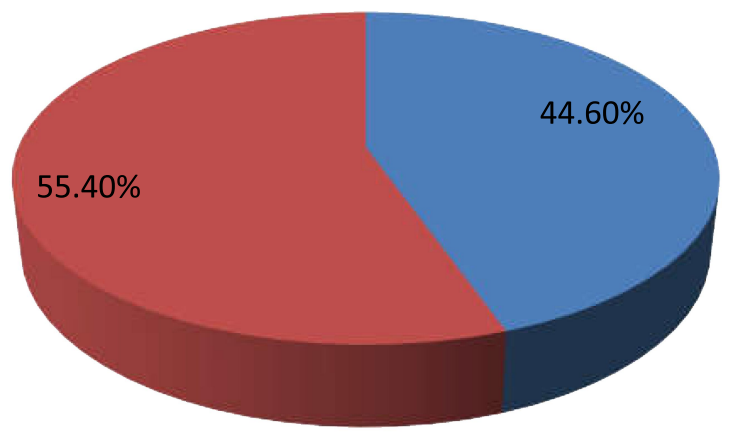

Patient satisfaction

Patient dissatisfaction

Figure 3 Prevalence of chronic patient's satisfaction who had follow-up visit at health facilities in North Shoa zone, Oromia region, from May I to June 30,2020 ( $=410$ ).

Patients who obtained sanitizer and alcohol for hand cleaning at the health facilities entrance were significantly associated with patient satisfaction inquiry. This may be due to COVID-19 infection prevention, and the control strategy is cleaning hands with chemicals like

Table 4 Chronic Disease Patient Satisfaction by Their Educational Status, Monthly Income, and Residence Who Had a Follow-Up Visit at Health Facilities in North Shoa Zone, Oromia Region, from May I to June 30, $2020(n=410)$

\begin{tabular}{|l|l|l|}
\hline Variables & Satisfied, $\mathbf{n}(\%)$ & Unsatisfied, $\mathbf{n}(\%)$ \\
\hline Level of Patient satisfaction by types of chronic diseases \\
\hline HIVIAIDS & $74(40.4)$ & $65(28.6)$ \\
Tuberculosis & $40(21.9)$ & $32(14.1)$ \\
Hypertension & $33(18)$ & $43(19)$ \\
Diabetes mellitus & $19(10.4)$ & $41(18.1)$ \\
Heart failure & $5(2.7)$ & $28(12.3)$ \\
Cancer & $1(0.6)$ & $6(2.6)$ \\
Others & $11(6)$ & $12(5.3)$ \\
\hline Level of Patient satisfaction by educational status \\
\hline Have no formal education & $98(53.5)$ & $114(50.2)$ \\
Primary school & $45(24.6)$ & $46(20.3)$ \\
Grade 9-I2 & $17(9.3)$ & $29(12.8)$ \\
Diploma and above & $23(12.6)$ & $38(16.7)$ \\
\hline Level of Patient satisfaction by monthly income \\
\hline$\leq 2000$ & $126(68.9)$ & $142(62.6)$ \\
\hline $\begin{array}{l}|l| \\
\text { 200I-5000 }\end{array}$ & $42(22.9)$ & $62(27.3)$ \\
$500 I-8000$ & $14(7.7)$ & $15(6.6)$ \\
$\geq 800$ I & $1(0.5)$ & $18(3.5)$ \\
\hline Level of Patient satisfaction by Residence area \\
\hline Urban & $82(44.8)$ & $120(52.9)$ \\
Rural & $101(55.2)$ & $(47.1)$ \\
\hline
\end{tabular}

alcohol and sanitizer. As patients become aware of this prevention strategy and unable to get at least one of them in the healthcare facilities may lead to dissatisfaction. ${ }^{3}$ Hence, this condition may be challenged for patients with chronic disease from their follow-up visits and exacerbate chronic illness.

Patients who maintained and observed better social distancing at the registration place, waiting for the outpatient department, laboratory, and pharmacy services as a means of the COVID-19 prevention in the healthcare facilities were significantly associated with patient satisfaction. The reason behind this fact is that because WHO and CDC identified as maintaining physical distancing are one of the COVID-19 prevention and control strategies. ${ }^{45,46}$ Therefore, patients who realized and maintained social distancing may increase patient satisfaction. In contrast, a lack of maintaining social distance (overcrowding) induces fear of being infected by COVID-19 at the health facilities may enhance dissatisfaction. ${ }^{14}$ This indicates that social/physical distancing measures are one of the mechanisms to minimize the fear of exposure to the COVID-19 in public health facilities.

\section{Conclusion}

The level of satisfaction for patients with chronic diseases is very low in the study area. Availability of sign and direction indicators, availability of ordering drugs, social distancing status in the healthcare facility, availability of alcohol, and sanitizer for hand cleaning at the healthcare facility entrance to prevent and control COVID-19 were factors associated with the satisfaction of patients with chronic diseases. Healthcare facilities need to work on the COVID-19 prevention and control 
Table 5 Factors Associated with Patient Satisfaction Among Chronic Disease Patients Who Had a Follow-Up Visit at Health Facilities in North Shoa Zone, Oromia Region, from May I to June 30, 2020 ( $n=410)$

\begin{tabular}{|c|c|c|c|c|}
\hline \multirow[t]{2}{*}{ Variables } & \multicolumn{2}{|c|}{ Level of Satisfaction } & \multirow[t]{2}{*}{ COR } & \multirow[t]{2}{*}{ AOR } \\
\hline & Satisfied & Unsatisfied & & \\
\hline \multicolumn{5}{|c|}{ Availability of ordered laboratory procedures } \\
\hline All in one & $92(62.2 \%)$ & $62(40.4 \%)$ & $0.83(0.29,2.36)$ & I.12 $(0.26,4.80)$ \\
\hline Some & $35(25.2)$ & $59(50.3 \%)$ & $3.54(1.30,9.61)^{* *}$ & $2.83(0.72,11.14)$ \\
\hline Not at all & $12(8.6 \%)$ & $30(9.3 \%)$ & 1 & I \\
\hline \multicolumn{5}{|c|}{ Availability of ordered drugs } \\
\hline All in one & $92(73.6 \%)$ & $65(41.1 \%)$ & $1.48(0.67,3.27)$ & I.48 $(0.42,5.23)$ \\
\hline Some & $27(21.6 \%)$ & 81 (39\%) & $3.7 \mathrm{I}(1.77,7.80)^{* *}$ & $3.7(\mathrm{I} . \mathrm{I}, \mathrm{I} 2.54)^{* *}$ \\
\hline Not at all & $6(4.8 \%)$ & 15 (19.9\%) & I & I \\
\hline \multicolumn{5}{|c|}{ Clinicians in interviewing by client language } \\
\hline Yes & 167 (91.3\%) & $180(979.3 \%)$ & $2.73(1.49,4.99)^{* *}$ & $0.75(0.24,2.33)$ \\
\hline No & $16(8.7 \%)$ & 47 (20.7\%) & 1 & I \\
\hline \multicolumn{5}{|c|}{ Availability of sign and direction indicator of location } \\
\hline Yes & 31 (16.9\%) & 70 (30.8\%) & $0.46(0.28,0.74)^{* *}$ & $3.26(1.1,9.92)^{* *}$ \\
\hline No & I52 (83.1\%) & 157 (69.20\%) & I & I \\
\hline \multicolumn{5}{|c|}{ Availability of water for handwashing at the entrance } \\
\hline Yes & 175 (95.6\%) & $190(83.7 \%)$ & $4.26(1.93,9.40)^{* *}$ & $3.59(0.60,21.44)$ \\
\hline No & $8(4.4 \%)$ & $37(16.3 \%)$ & 1 & I \\
\hline \multicolumn{5}{|c|}{ Availability of soap for handwashing at the entrance } \\
\hline Yes & $163(89.1 \%)$ & $168(74 \%)$ & $2.86(I .65,4.97)^{* *}$ & $1.65(0.49,5.54)$ \\
\hline No & $20(10.9 \%)$ & $59(26 \%)$ & 1 & I \\
\hline \multicolumn{5}{|c|}{ Alcohol for hand cleaning at the entrance } \\
\hline Yes & $75(41 \%)$ & $49(21.6 \%)$ & $5.52(1.64,3.89)^{* *}$ & $2.66(1.1,6.65)^{* *}$ \\
\hline No & $108(59 \%)$ & 178 (78.4\%) & 1 & I \\
\hline \multicolumn{5}{|c|}{ Sanitizer available at the entrance of health facility } \\
\hline Yes & 147 (80.30\%) & $|2|(53.3 \%)$ & $1.67(1.10,2.66)^{* *}$ & $4.45(1.72,|1| .52)^{* *}$ \\
\hline No & $36(19.70 \%)$ & $106(46.7 \%)$ & I & I \\
\hline \multicolumn{5}{|c|}{ Keeping social distance in the health facility } \\
\hline Yes & 149 (8I.4\%) & $|2|(53.3 \%)$ & $3.84(2.44,6.05)^{* *}$ & $2.63(1.21,5.70)^{* *}$ \\
\hline No & $34(18.6 \%)$ & $106(46.7 \%)$ & 1 & I \\
\hline \multicolumn{5}{|c|}{ Clinicians wearing a face mask } \\
\hline Yes & $176(96.20 \%)$ & $191(84.1 \%)$ & $4.74(2.06,10.92)^{* *}$ & $0.76(0.12,5.07)$ \\
\hline No & $7(3.8 \%)$ & $36(15.9 \%)$ & 1 & 1 \\
\hline \multicolumn{5}{|c|}{ Clinicians wearing gloves when giving healthcare } \\
\hline Yes & $170(92.9 \%)$ & $160(70.5 \%)$ & $5.48(2.91,10.30)^{* *}$ & $0.8 \mathrm{I}(0.2 \mathrm{I}, 3.05)$ \\
\hline No & $13(7.1 \%)$ & $67(29.5 \%)$ & 1 & I \\
\hline
\end{tabular}

(Continued) 
Table 5 (Continued).

\begin{tabular}{|c|c|c|c|c|}
\hline \multirow[t]{2}{*}{ Variables } & \multicolumn{2}{|c|}{ Level of Satisfaction } & \multirow[t]{2}{*}{ COR } & \multirow[t]{2}{*}{ AOR } \\
\hline & Satisfied & Unsatisfied & & \\
\hline \multicolumn{5}{|c|}{ Clinician rub their hands with alcohol or sanitizer } \\
\hline Yes & $17 \mid(93.4 \%)$ & $178(78.4 \%)$ & $3.92(2.02,7.63)^{* *}$ & $1.58(0.37,6.77)$ \\
\hline No & $12(6.6 \%)$ & $49(21.6 \%)$ & I & I \\
\hline \multicolumn{5}{|c|}{ Availability of health education at the health facility } \\
\hline Yes & $157(85.8 \%)$ & 138 (60.8\%) & $3.89(2.38,6.38)^{* *}$ & $\mathrm{I} .14(0.5 \mathrm{I}, 2.56)$ \\
\hline No & $26(14.2 \%)$ & $89(39.2 \%)$ & 1 & I \\
\hline \multicolumn{5}{|c|}{ Screening for COVID-I 9 at health facility } \\
\hline Yes & $168(91.8 \%)$ & $183(80.6 \%)$ & $2.69(1.45,5.02)^{* *}$ & $1.3(0.34,5.05)$ \\
\hline No & $15(8.2 \%)$ & $44(19.4 \%)$ & I & I \\
\hline
\end{tabular}

Notes: I=reference, and **Statistically significant at $\mathrm{p}$-value $<0.05$ in bivariable and multivariable logistic regression, Hosmer and Lemeshow test $=0.850$.

strategy like maintaining social distance, availing drugs, alcohols, and sanitizers at the healthcare facilities entrance, conducting regular customer satisfaction assessment, and monitoring feedback regularly mandatory.

\section{Abbreviations}

AOR, Adjusted Odds Ratio; CI, Confidence Interval; COVID-19, Corona Virus Disease-2019; MPH, Master of Public Health; OPD, Outpatient department; OR, Odds ratio; SPSS, Statistical Package for Social Science; WHO, World Health Organization.

\section{Data Sharing Statement}

The data for this study are cannot be made publically available at present.

It will be made available from the corresponding author on a reasonable request.

\section{Ethics Approval and Consent to Participate}

This study was conducted in accordance with the Declaration of Helsinki. Salale University approved the ethical clearance of verbal informed consent and assent. A support letter was obtained from the North Shoa zone health office, and oral informed consent was obtained from the study participants whose age $\geq 18$ years. The assent was obtained from parents/guardians for 15 to 18 years old after clearing-up about the study's objective and purpose for each study participant. The privacy and confidentiality of study participants were also be maintained strictly. Data collectors were informed about coding the questionnaire and not writing the study participants' names.

\section{Acknowledgments}

The authors acknowledge Salale University, all health facilities from where data were collected, and study participants for their cooperation.

\section{Author Contributions}

All authors made a significant contribution to the conception, study design, execution, and acquisition of data, analysis, and interpretation. All authors involved in drafting, revising, or critically reviewing the article; gave final approval of the version to be published; have agreed on the journal to which the article has been submitted; and agree to be accountable for all aspects of the work.

\section{Funding}

Salale University funds this research work. The funders had no role in study design, data collection, analysis, decision to publish, or manuscript preparation.

\section{Disclosure}

The authors declare that they have no competing interests for this work.

\section{References}

1. Bjertnaes OA, Sjetne IS, Iversen HH. Overall patient satisfaction with hospitals: effects of patient-reported experiences and fulfilment of expectations. BMJ Qual Saf. 2012;21(1):39-46. doi:10.1136/bmjqs2011-000137 
2. Alkureishi MA, Lee WW, Lyons M, et al. Impact of electronic medical record use on the patient-doctor relationship and communication: a systematic review. J Gen Intern Med. 2016;31 (5):548-560. doi:10.1007/s11606-015-3582-1

3. Berkowitz B. The patient experience and patient satisfaction: measurement of a complex dynamic. Online J Issues Nurs. 2016;21(1).

4. Gill L, White L. A Critical Review of Patient Satisfaction. Leadership in Health Services; 2009.

5. Busse R. Understanding satisfaction, responsiveness and experience with the health system. Health system performance comparison: an agenda for policy, information and research. 2013:255-280.

6. World Health Organization. World Health Statistics 2013: A Wealth of Information on Global Public Health. World Health Organization; 2013.

7. Gorbalenya A, Baker SC, Baric RS, et al. Severe a cute respiratory syndrome. related coronavirus: the species and its viruses a statement of the coronavirus study Group; 2020.

8. Hoffmann M, Kleine-Weber H, Schroeder S, et al. SARS-CoV-2 cell entry depends on ACE2 and TMPRSS2 and is blocked by a clinically proven protease inhibitor. Cell. 2020;181(2):271-280.e8. doi:10.10 16/j.cell.2020.02.052

9. Kruk ME, Ataguba JE, Akweongo P. The universal health coverage ambition faces a critical test. Lancet. 2020. doi:10.1016/S01406736(20)31795-5

10. Monasta L, Abbafati C, Logroscino G, et al. Italy's health performance, 1990-2017: findings from the Global Burden of Disease Study 2017. Lancet Public Health. 2019;4(12):e645-e57. doi:10.10 16/S2468-2667(19)30189-6

11. Lozano R, Fullman N, Mumford JE, et al. Measuring universal health coverage based on an index of effective coverage of health services in 204 countries and territories, 1990-2019: a systematic analysis for the Global Burden of Disease Study 2019. Lancet. 2020.

12. Onder G, Rezza G, Brusaferro S. Case-fatality rate and characteristics of patients dying in relation to COVID-19 in Italy. JAMA. 2020. doi:10.1001/jama.2020.4683

13. Ferguson N, Laydon D, Nedjati Gilani G, et al. Report 9: impact of non-pharmaceutical interventions (NPIs) to reduce COVID19 mortality and healthcare demand; 2020.

14. Makoni M. Africa prepares for coronavirus. Lancet. 2020;395 (10223):483. doi:10.1016/S0140-6736(20)30355-X

15. Monitor I COVID-19 and the world of work. Updated estimates and analysis; 2020. Available from: https://www.ilo.org/wcmsp5/groups/ public.

16. Valentine N, Verdes-Tennant E, Bonsel G. Health systems' responsiveness and reporting behaviour: multilevel analysis of the influence of individual-level factors in 64 countries. Soc Sci Med. 2015;138:152-160. doi:10.1016/j.socscimed.2015.04.022

17. Bragazzi NL, Riccò M, Pacifico A, Malagoli P. COVID19 Dermatological Task Force YDIN, Kridin K, et al. COVID-19 knowledge prevents biologics discontinuation: data from an Italian multicenter survey during RED-ZONE declaration. Dermatol Ther. 2020: e13508.

18. Gironi LC, Boggio P, Giorgione R. et al. The impact of COVID-19 pandemics on dermatologic surgery: real-life data from the Italian Red-Zone. J Dermatol Treat. 2020:1-7. doi:10.1080/09546634. 2020.1789044

19. Alemayehu YK, Bushen OY, Muluneh AT. Evaluation of HIV/AIDS clinical care quality: the case of a referral hospital in North West Ethiopia. Int J Qual Health Care. 2009;21(5):356-362. doi:10.1093/ intqhe/mzp030

20. Getenet H, Haileamlak A, Tegegn A. Clients'satisfaction with anti retroviral therapy services at jimma university specialized hospital. Ethiop J Health Sci. 2008;18(2).

21. Gillman-Wells CC, Sankar TK, Vadodaria S. COVID-19 reducing the risks: telemedicine is the new norm for surgical consultations and communications. Aesthetic Plast Surg. 2020:1-6.
22. Cinelli E, Fabbrocini G, Fattore D, Marasca C, Damiani G, Annunziata MC. Safe distance, safe patients! Therapeutic management of oncological patients affected by cutaneous and mucosal adverse events during the COVID-19 pandemic: an Italian experience. Support Care Cancer. 2020;1.

23. Ashry AH, Alsawy MF. Doctor-patient distancing: an early experience of telemedicine for postoperative neurosurgical care in the time of COVID-19. Egypt J Neurol Psychiatr Neurosurg. 2020;56(1):1-8. doi: 10.1186/s41983-020-00212-0

24. Cristaudo A, Pigliacelli F, Pacifico A, Damiani G, Iacovelli P, Morrone A. Teledermatology and hygiene practices during the COVID-19 pandemic. Contact Dermatitis. 2020. doi:10.1111/cod.13683

25. Kaur D, Galloway GK, Oyibo SO. Patient satisfaction with the use of telemedicine in the management of hyperthyroidism. Cureus. 2020;12(8).

26. Mullan Z. Transforming health care in Ethiopia. Lancet Glob Health. 2016;4(1):e1. doi:10.1016/S2214-109X(15)00300-9

27. Gedefaw M, Setargie F, Awoke W. Satisfaction of chronic illness patients at Felege Hiwot Referral Hospital, Bahir Dar City, Northwest Ethiopia. Open J Epidemiol. 2014;4(04):217. doi:10.4236/ojepi.20 14.44028

28. Webster TR, Mantopoulos J, Jackson E, et al. A brief questionnaire for assessing patient healthcare experiences in low-income settings. Int $J$ Qual Health Care. 2011;23(3):258-268. doi:10.1093/intqhe/mzr019

29. Andaleeb SS, Siddiqui N, Khandakar S. Patient satisfaction with health services in Bangladesh. Health Policy Plan. 2007;22 (4):263-273. doi:10.1093/heapol/czm017

30. Girmay A Assessment of clients' satisfaction with outpatient services in Tigray Zonal Hospitals. 2006. 2014.

31. Assefa F, Mosse A. Assessment of clients' satisfaction with health service deliveries at Jimma University specialized hospital. Ethiop $J$ Health Sci. 2011;21(2):101-110. doi:10.4314/ejhs.v21i2.69050

32. Tume SM, Salgedo WB, Jaleta FT. Patient satisfaction and associated factors with outpatient medical services in rural primary healthcare facilities, Ilubabor zone, Oromiya region, south West Ethiopia. Int J Curr Res. 2015;7(9):20245-20251.

33. Babure ZK, Jiru FA, Weldemarium TD. Client satisfaction among private wing and regular health care services at Nekemte Referral Hospital, East Wollega Zone, Oromia regional state, Western Ethiopia: A comparative cross-sectional study, 2016. J Public Health Epidemiol. 2018;10(2):43-61. doi:10.5897/JPHE2017.0979

34. Anteneh A, Andargachew K, Muluken D. Patient satisfaction with outpatient health services in Hawassa university teaching hospital, southern Ethiopia. J Public Health Epidemiol. 2014;6(2):101-110. doi:10.5897/JPHE2013.0613

35. Mezemir R, Getachew D, Gebreslassie M. Patients' satisfaction and its determinants in outpatient Department of Deberebirhan Referral Hospital, north Shoa, Ethiopia. Int J Econ Manag Sci. 2014;3(191):2. doi:10.4172/2162-6359.1000191

36. Sagaro GG, Yalew AW, Koyira MM. Patients' satisfaction and associated factors among outpatient Department at Wolaita Sodo University Teaching Hospital, Southern Ethiopia: a cross sectional study. Sci J Clin Med. 2015;4(5):109-116. doi:10.11648/j.sjcm.20 150405.16

37. Udonwa NE, Ogbonna UK. Patient-related factors influencing satisfaction in the patient-doctor encounters at the general outpatient clinic of the university of calabar teaching hospital, calabar, Nigeria. Int J Family Med. 2012:2012.

38. Rajbanshi L, Dungana G, Gurung Y, Koirala D. Satisfaction with health care services of out patient department at Chitwan Medical College Teaching Hospital, Nepal. J Chitwan Med Coll. 2014;4 (1):11-18. doi:10.3126/jcmc.v4i1.10841

39. Olomi GA, Mboya IB, Manongi RN. Patients' Level of Satisfaction with the Health Care Services Received at Outpatient Departments in Kilimanjaro Region, Tanzania. J Patient Care. 2017;10:4172/25734598.1000124 . 
40. Maliha N, Aysha Z, Shaikh B. Determinants of patient's satisfaction with health care system in Pakistan: a critical review. Pak J Public Health. 2012;2(2):56-61.

41. Geberu DM, Biks GA, Gebremedhin T, Mekonnen TH. Factors of patient satisfaction in adult outpatient departments of private wing and regular services in public hospitals of Addis Ababa, Ethiopia: a comparative cross-sectional study. BMC Health Serv Res. 2019;19 (1):869. doi:10.1186/s12913-019-4685-X

42. Berehe TT, Bekele GE, Yimer YS, Lozza TZ. Assessment of clients satisfaction with outpatient services at Yekatit 12 hospital medical college, Addis Ababa, Ethiopia. BMC Res Notes. 2018;11(1):507. doi:10.1186/s13104-018-3603-3

43. Ambelie YA, Demssie AF, Gebregziabher MG. Patients' satisfaction and associated factors among private wing patients at Bahirdar Felege Hiwot Referral Hospital, North West Ethiopia. Sci J Public Health. 2014;2(5):417-423. doi:10.11648/j.sjph.20140205.17
44. Mohd A, Chakravarty A. Patient satisfaction with services of the outpatient department. Med J Armed Forces India. 2014;70 (3):237-242. doi:10.1016/j.mjafi.2013.06.010

45. Ahmed F, Zviedrite N, Uzicanin A. Effectiveness of workplace social distancing measures in reducing influenza transmission: a systematic review. BMC Public Health. 2018;18(1):518. doi:10.1186/s12889018-5446-1

46. Novel CPERE. The epidemiological characteristics of an outbreak of 2019 novel coronavirus diseases (COVID-19) in China. Zhonghua Liu Xing Bing Xue Za Zhi= Zhonghua Liuxingbingxue Zazhi. 2020;41 (2): 145 .

\section{Publish your work in this journal}

Patient Preference and Adherence is an international, peer-reviewed, open access journal that focusing on the growing importance of patient preference and adherence throughout the therapeutic continuum. Patient satisfaction, acceptability, quality of life, compliance, persistence and their role in developing new therapeutic modalities and compounds to optimize clinical outcomes for existing disease states are major areas of interest for the journal. This journal has been accepted for indexing on PubMed Central. The manuscript management system is completely online and includes a very quick and fair peer-review system, which is all easy to use. Visit http:// www.dovepress.com/testimonials.php to read real quotes from published authors. 